\title{
APPLICATION OF RIGID-BODY NUMERICAL SIMULATIONS FOR MODELLING WHEEL-RAIL CONTACT INTERACTIONS AND 3D MOVING LOAD ANALYSES
}

\author{
M. ROSHAN KHAN \& SATYANARAYANA MURTY DASAKA \\ Indian Institute of Technology Bombay, India
}

\begin{abstract}
High speed railway lines of present day operate with longer, heavier trains at super-fast speeds. The dynamic loading conditions imposed by these trains impose a large impact on the substructure, making the characterization of loads a very important aspect. Numerical modelling of railway track systems can considerably reduce the time and costs associated with performance analysis of railway tracks subjected to dynamic loading conditions. However, finely detailed numerical models expend a lot of computational resources and time for effectively simulating railway loading on tracks. A numerical model has been developed for evaluating the suitability of rigid-body simulations to model wheel-rail contact interactions and performing 3D moving load analyses. Transient analyses are performed in ANSYS, with the model simulating an Indian Railway WAP-7 locomotive wheel-set running on IRS-52 railway track section. Validation of the numerical model is done with the wheel-rail contact pressure results available from the literature, for a loaded section of Italian rail section UNI-60. Static analysis of the WAP-7 locomotive wheel-set has been done for an axle load of 20.5 tonnes and the wheel-rail contact patch has been construed with estimation of the interface contact pressures. Further, 3D transient moving load model was developed, simulating the actual wheel-rolling movement on rails, based on the interface contact friction. The analysis was performed on an Integrated Coach Factory (ICF) bogie wheel-set, simulating the coach to run at a speed of $140 \mathrm{~km} / \mathrm{h}$ and an axle load of 20.3 tonnes; the maximum speed and axle load with which train coaches are allowed to operate today in Indian Railways. The model was found to have lesser computational demands and CPU time was reduced to one-twentieth in comparison with deformable-body analyses, yielding very reliable results. Rigid-body numerical modelling proved to be an effective alternative to the practice of finely meshed finite element modelling of railway track systems.

Keywords: rigid-body simulation, railway loading, wheel-rail interface, contact pressure, 3D moving load analysis.
\end{abstract}

\section{INTRODUCTION}

The rapid growth in population has globally imposed a very large demand on the operation frequency of trains to serve more number of passengers and large freight. Trains have become heavier and longer with blazing fast travelling speeds. These dynamic loading conditions impose very different kinds of loading onto the track substructure and diverse physical studies need to be performed for simulating the behaviour under each loading condition. Numerical finite element modelling can reduce the time and costs associated with physical testing of railway tracks. The method relies on the simulation of prototype behaviour by considering the bodies to be discretized into a number of component elements associated with each other. Larger numbers of such elements in the models make the analyses consume considerable amount of time and computational resources, both of which would not be in-hand during closely scheduled project planning phases. This study considers the application of multi-body simulation with rigid body elements to estimate the analysis results, which comes out with much greater computational ease and speed. The method would be very apposite, if the stresses and strains inside the bodies are out of the scope of study. 
The present study covers the rigid-body simulation of an Indian railway track section IRS 52 loaded with the axle of a high speed WAP-7 train locomotive hauling ICF bogies at a maximum operational speed of $140 \mathrm{~km} / \mathrm{h}$. Contact stress analyses are performed at the wheelrail interface, and the pressures induced at the interface during loading has been estimated. Development of a 3D moving load model is also done, based on the actual wheel rolling movement simulated using wheel-rail interface friction. The necessity and advantages of using this method has been discussed in the following sections, several limitations encountered in conventional wheel-rail modelling practices are also discussed. The model can further be extended for analysis of wheel-rail contact stresses induced for different axle loads considered at varying operational speeds.

\subsection{Necessity of 3D moving load modelling}

Review of literature on numerical modelling practices in railroad engineering [1] - [11]; revealed that the concept of considering the moving train wheel loads as equivalent set of moving point loads or line loads on the rail has been in practice for long. The limitations encountered in the studies were reviewed and the necessity of a 3-dimensional model, that can simulate actual train wheel-rolling movement and loading on rails, was clearly identified.

Following are the advantages of using a 3D moving wheel load model:

- No simplification of loads and geometry required from 3D to 2D.

- Distribution of loads and stress profiles can be evaluated.

- Shear effects induced by wheels rolling on rails can be considered.

- Wheel-rail contact pressure analysis can be done.

- Contact interface friction and wearing of wheels/rails can be considered.

- Acceleration/deceleration of a train can be modelled.

- An initial velocity condition: ' $\mathrm{x}$ ' $\mathrm{km} / \mathrm{h}$ at time $\mathrm{t}=0$, can be considered.

- Inertial effects of moving masses can be considered.

\subsection{Advantages of rigid-body analysis}

Multi-rigid-body analyses are fast simulation methods for interconnected rigid body interactions, and are useful in analysing the relative translational and rotational displacements undergone by the bodies during load application. The concept was first developed by Newton, considering multiple-body interactions and the reaction forces between the bodies were introduced by Euler. The numerical method considers solids as rigid bodies and hence the deformations of the body are not basically considered. This method specially comes handy when the geometries modelled are of very large dimensions or when the interactions of a large number of interconnected bodies need to be carried out. The method however does not yield any results for the stresses and strains developed within the body, if that falls within scope. The advantage of this method is that it overcomes the difficulty of analysing a large number of discrete nodes and elements within the bodies, which in turn reduces the huge amount of time and computational resources required for successful completion of the numerical analysis. The method considers the connection between bodies using kinematic constraints or force elements and the unilateral constraint of Coulomb's friction between bodies can also be defined. The solver relies on the equations of motion for model analysis. 


\section{NUMERICAL RIGID-BODY MODELLING AND VALIDATION}

Geometric modelling of the wheel-rail systems were performed in software SOLIDWORKS 2016, with the dimensions for wheels, axle and rails as specified by the Research Design and Standards Organization (RDSO) [12], [13]. RDSO is constituted under the Ministry of Railways in India, and functions as the consultant and technical advisor in all the design and standardization practices for railway equipment and all the issues related with construction, operation and maintenance of railway lines.

Finite element specifications were defined on the geometrical models developed using software ANSYS 16.1, Workbench module. Transient structural analysis was selected for solution of all the models and finite element models were first considered with all bodies as either deformable or with all bodies as rigid. It was seen that when bodies were considered deformable, 3D moving load analyses were not able to execute successfully, since analyses were terminating randomly due to very high processing, caching and storage demands from the computing system. It was also noted that very fine meshing is required in exact simulation of contact interfaces, resulting in a very large number of nodes and elements, with high computational time and resources associated. This was especially the case observed when moving load analyses were considered on longer rail sections. The suitability of rigid-body dynamic analyses was thus justified, since computation of internal stresses produced in the bodies and their deformations were not within the scope of this study.

\subsection{Numerical modelling of Italian rail UNI-60}

The modelling of Italian rail section was first done, for validating the model with data available from investigations conducted by Pau et al. [14] on a section of UNI-60 rail loaded with a wheel of $260 \mathrm{~mm}$ diameter, for an applied load range of $0-10,000 \mathrm{~N}$. The load contact pressure curve obtained from that experiment was considered as the reference for model validation in this study. Geometrical model of UNI-60 rail was developed in software SOLIDWORKS, with a wheel diameter of $260 \mathrm{~mm}$. The model was then imported into ANSYS for applying material properties, loads and boundary conditions. The geometric model developed for UNI-60 rail is shown in Fig. 1.

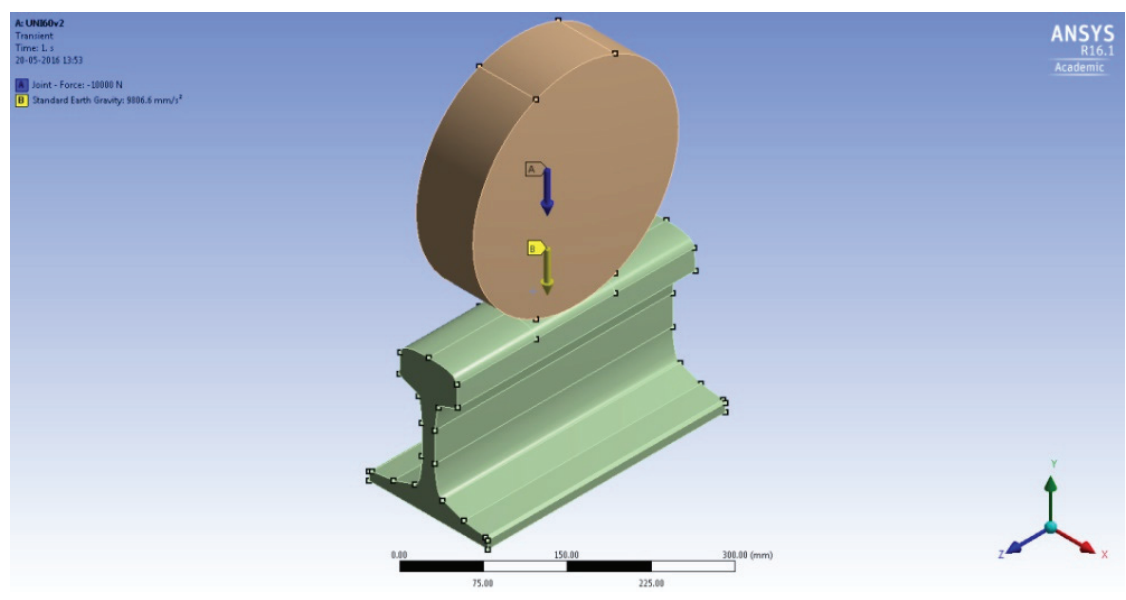

Figure 1: Geometric model of UNI-60 rail with $260 \mathrm{~mm}$ diameter wheel. 


\subsection{Validation of numerical model UNI-60}

In the numerical analysis performed by Pau et al. [14], kinematic hardening model was chosen in ANSYS with a yield stress of $300 \mathrm{MPa}$ and the tangential modulus was taken as $1 / 10$ th of the elastic modulus. The contact interface was considered to be frictionless and a $2 \mathrm{D}$ analysis was performed. The same material behaviour is simulated in the $3 \mathrm{D}$ model developed in this study and the contact interface section in the model is cut at both wheel and rail surfaces near contact area, for detailed definition of the contact interface. Loads were applied in ten stages from 0 to $10,000 \mathrm{~N}$ (in steps of $1000 \mathrm{~N}$ ). The optimum size for contact meshing was found by running over 200 analyses, with surface mesh sizes down from 50 $\mathrm{mm}$ and it was found that contact definitions required mesh sizes smaller than $1 \mathrm{~mm}$ for simulating results validated with the data available in the literature. The results of 154 analyses performed for mesh sizes from $1 \mathrm{~mm}$ to $0.5 \mathrm{~mm}$ are presented in Tables 1 and 2 . Every mesh size was run with two sets of analyses; one without considering acceleration due to earth's gravity ( $\mathrm{g}$ ) and one with ' $\mathrm{g}$ ' applied in addition to axle load. Table 1 gives the contact pressure results obtained without considering ' $\mathrm{g}$ ' in loading conditions and the results for analyses incorporating ' $\mathrm{g}$ ' are given in Table 2 . From the analyses, results were found to be closer to reference values when ' $g$ ' was not considered in the load definition. However, the effect of gravity on earth cannot be overlooked and hence it was decided that the best mesh size from the test results will be chosen taking acceleration due to gravity ' $\mathrm{g}$ ' into account.

Regression analyses were performed for all sets of data and the mesh size with the highest $\mathrm{R}^{2}$ value and minimum values for AIC and BIC (Akaike and Bayesian Information Criterion, respectively) was considered to be chosen for all further analyses. Table 3 gives the calculated $\mathrm{R}^{2}$ values for different mesh sizes. The ideal value of $\mathrm{R}^{2}$ needs to be close to unity and it can be seen that the mesh size of $0.8 \mathrm{~mm}$ (considering ' $\mathrm{g}$ ') had largest $\mathrm{R}^{2}$ value of 0.94940 , at a significance level of $5 \%$. The p-value was calculated as $1.83 \times 10^{-6}$, which is less than the maximum value of 0.05 for a significance level of $5 \%$. The AIC and BIC for

Table 1: Contact pressures obtained for wheel-rail contact element sizes: $1 \mathrm{~mm}$ to $0.5 \mathrm{~mm}$ without considering ' $\mathrm{g}$ ' in loading conditions.

\begin{tabular}{|l|l|l|l|l|l|l|l|l|}
\hline \multicolumn{2}{|l|}{ Reference contact pressures } & \multicolumn{6}{|l|}{ Mesh sizes adopted and contact pressure results (MPa) } \\
\hline $\begin{array}{l}\text { Load } \\
(\mathrm{N})\end{array}$ & $\begin{array}{l}\text { Contact Pressure } \\
(\mathrm{MPa}) \\
(\text { Pau et al., 2002) }\end{array}$ & $\begin{array}{l}1 \\
\mathrm{~mm}\end{array}$ & $\begin{array}{l}0.9 \\
\mathrm{~mm}\end{array}$ & $\begin{array}{l}0.8 \\
\mathrm{~mm}\end{array}$ & $\begin{array}{l}0.75 \\
\mathrm{~mm}\end{array}$ & $\begin{array}{l}0.7 \\
\mathrm{~mm}\end{array}$ & $\begin{array}{l}0.6 \\
\mathrm{~mm}\end{array}$ & $\begin{array}{l}0.5 \\
\mathrm{~mm}\end{array}$ \\
\hline 0 & 0 & 0 & 0 & 0 & 0 & 0 & 0 & 0 \\
\hline 1000 & 299 & 225 & 238 & 252 & 261 & 272 & 318 & 342 \\
\hline 2000 & 523 & 337 & 357 & 385 & 403 & 423 & 459 & 502 \\
\hline 3000 & 688 & 429 & 462 & 500 & 515 & 531 & 576 & 635 \\
\hline 4000 & 766 & 518 & 556 & 586 & 605 & 625 & 682 & 743 \\
\hline 5000 & 768 & 596 & 628 & 665 & 686 & 712 & 776 & 842 \\
\hline 6000 & 825 & 662 & 696 & 738 & 762 & 792 & 856 & 934 \\
\hline 7000 & 885 & 721 & 758 & 807 & 833 & 859 & 933 & 1015 \\
\hline 8000 & 950 & 776 & 820 & 873 & 896 & 922 & 1005 & 1089 \\
\hline 9000 & 981 & 829 & 878 & 929 & 955 & 983 & 1075 & 1162 \\
\hline 10000 & 1020 & 882 & 935 & 983 & 1011 & 1042 & 1141 & 1232 \\
\hline
\end{tabular}


Table 2: Contact pressures obtained for wheel-rail contact element sizes: $1 \mathrm{~mm}$ to $0.5 \mathrm{~mm}$ considering ' $\mathrm{g}$ ' in loading conditions.

\begin{tabular}{|l|l|l|l|l|l|l|l|l|}
\hline \multicolumn{2}{|l|}{ Reference contact pressures } & \multicolumn{6}{|l|}{ Mesh sizes adopted and contact pressure results (MPa) } \\
\hline $\begin{array}{l}\text { Load } \\
(\mathrm{N})\end{array}$ & $\begin{array}{l}\text { Contact pressure } \\
\text { (MPa) } \\
\text { (Pau et al., 2002) }\end{array}$ & $\begin{array}{l}1 \\
\mathrm{~mm}\end{array}$ & $\begin{array}{l}0.9 \\
\mathrm{~mm}\end{array}$ & $\begin{array}{l}0.8 \\
\mathrm{~mm}\end{array}$ & $\begin{array}{l}0.75 \\
\mathrm{~mm}\end{array}$ & $\begin{array}{l}0.7 \\
\mathrm{~mm}\end{array}$ & $\begin{array}{l}0.6 \\
\mathrm{~mm}\end{array}$ & $\begin{array}{l}0.5 \\
\mathrm{~mm}\end{array}$ \\
\hline 0 & 0 & 103 & 116 & 127 & 132 & 137 & 160 & 172 \\
\hline 1000 & 299 & 260 & 277 & 294 & 306 & 319 & 365 & 393 \\
\hline 2000 & 523 & 364 & 391 & 421 & 440 & 458 & 495 & 544 \\
\hline 3000 & 688 & 456 & 490 & 527 & 542 & 560 & 609 & 669 \\
\hline 4000 & 766 & 541 & 578 & 609 & 630 & 651 & 713 & 773 \\
\hline 5000 & 768 & 617 & 648 & 687 & 709 & 737 & 800 & 870 \\
\hline 6000 & 825 & 681 & 714 & 759 & 784 & 813 & 879 & 959 \\
\hline 7000 & 885 & 737 & 777 & 826 & 852 & 878 & 954 & 1037 \\
\hline 8000 & 950 & 791 & 838 & 890 & 914 & 940 & 1025 & 1111 \\
\hline 9000 & 981 & 844 & 895 & 945 & 972 & 1000 & 1095 & 1182 \\
\hline 10000 & 1020 & 897 & 951 & 998 & 1027 & 1058 & 1158 & 1252 \\
\hline
\end{tabular}

Table 3: Regression analysis for validation of UNI-60 rail model.

\begin{tabular}{|l|l|l|l|l|}
\hline Mesh Size & $\begin{array}{l}\mathrm{R}^{2} \text { value } \\
\text { (without 'g') }\end{array}$ & $\begin{array}{l}\text { Significance F } \\
\text { (without 'g') }\end{array}$ & $\begin{array}{l}\mathrm{R}^{2} \text { value } \\
\text { (with 'g') }\end{array}$ & $\begin{array}{l}\text { Significance F } \\
\text { (with 'g') }\end{array}$ \\
\hline $1 \mathrm{~mm}$ & 0.94427 & $2.69818 \times 10^{-6}$ & 0.94262 & $3.03382 \times 10^{-6}$ \\
\hline $0.9 \mathrm{~mm}$ & 0.94942 & $1.82749 \times 10^{-6}$ & 0.94623 & $2.33678 \times 10^{-6}$ \\
\hline $0.8 \mathrm{~mm}$ & 0.95319 & $1.33855 \times 10^{-6}$ & 0.94940 & $1.82953 \times 10^{-6}$ \\
\hline $0.75 \mathrm{~mm}$ & 0.95358 & $1.29347 \times 10^{-6}$ & 0.94914 & $1.86745 \times 10^{-6}$ \\
\hline $0.7 \mathrm{~mm}$ & 0.95311 & $1.34775 \times 10^{-6}$ & 0.94896 & $1.89447 \times 10^{-6}$ \\
\hline $0.6 \mathrm{~mm}$ & 0.94453 & $2.6483 \times 10^{-6}$ & 0.94213 & $3.14001 \times 10^{-6}$ \\
\hline $0.5 \mathrm{~mm}$ & 0.94985 & $1.76575 \times 10^{-6}$ & 0.94646 & $2.29674 \times 10^{-6}$ \\
\hline
\end{tabular}

this mesh size was computed as 82.058 and 82.663 , respectively, which had lower values in comparison with the other mesh sizes that went up to the values of 86.571 and 87.176 respectively, for the mesh size of $0.5 \mathrm{~mm}$. Hence it was decided that the mesh size of $0.8 \mathrm{~mm}$ will be optimally used for contact element definitions in further analysis of Indian Railway models, since validated contact pressure results for loads beyond $10000 \mathrm{~N}$ is not available in the literature.

\section{NON-LINEAR RIGID-BODY ANALYSIS OF INDIAN RAILWAY MODEL}

The numerical simulation of an Indian Railway locomotive wheel-set running on IRS 52 rail section was considered. The geometric model was developed with the specifications and dimensions specified by RDSO for the axle, wheels and rails.

\subsection{Model dimensions and material definition}

The geometric model of rail is developed with cross-section of IRS 52 rails. Broad gauge spacing of $1676 \mathrm{~mm}$ is considered and the coning of rails is modelled inwards by a slope of 
1 in 20. Coning of rails are provided, so that the load acting from coned (sloping) surface of wheels are transferred axially along the vertical central axis of rails. Indian railway uses 90 UTS steel rails. The properties of material used in modelling is tabulated in Table 4 and the model has been assigned with bilinear isotropic hardening behaviour. The value of yield strength is defined and the Tangent modulus is considered as $1 / 10^{\text {th }}$ of the Elastic modulus. A small rail length of $1 \mathrm{~m}$ is considered for the static model, since no wheel rolling needs to be simulated. The geometry of wheel-set is based on the specifications given by RDSO for rolling gear [15].

\subsection{Meshing}

A geometrically mapped meshing is done for both the wheel-rail interface and axle-wheel interface, for obtaining meshes that perfectly arrange with the shape of the surface being meshed. The option to check topology was also enabled in the settings. Trial analyses showed that considering axle as a deformable or rigid body did not make a significant difference in the contact interface results obtained at wheel-rail interface. So the axle was considered as a deformable body for assigning the axle load. The following mesh sizes were adopted in this model:

- Wheel-rail interface: $0.8 \mathrm{~mm}$

- Axle-wheel interface: $15 \mathrm{~mm}$

- Axle (body): $15 \mathrm{~mm}$

\subsection{Contact modelling}

Realistic simulation of the wheel-rail contact interface was an important aspect of this study. The model had a total of four contact interfaces, two at the wheel-rail interface and two at the axle-wheel interfaces. However, it was seen that changes in the meshing of axle-wheel interface had very less effect on the overall model behaviour.

Wheel-rail interface was modelled as a 'frictional' contact with asymmetric behaviour. The wheel was considered as contact body and rail was considered as the target. A frictional coefficient of 0.4 was assigned for the steel-steel interface. Augmented Lagrange formulation was selected to enable contact pressure calculations and normal stiffness was left to the

Table 4: Properties of the 90 UTS steel used in model.

\begin{tabular}{|l|l|l|}
\hline Property & Value & Unit \\
\hline Density & 7850 & $\mathrm{~kg} / \mathrm{m}^{3}$ \\
\hline Young's modulus & $2 \times 10^{5}$ & $\mathrm{MPa}$ \\
\hline Poisson's ratio & 0.3 & - \\
\hline Bulk modulus & $1.66 \times 10^{5}$ & $\mathrm{MPa}$ \\
\hline Shear modulus & $7.69 \times 10^{4}$ & $\mathrm{MPa}$ \\
\hline Bilinear isotropic hardening yield strength & 250 & $\mathrm{MPa}$ \\
\hline Tangent modulus & $2 \times 10^{4}$ & $\mathrm{MPa}$ \\
\hline Ultimate tensile strength & 883 & $\mathrm{MPa}$ \\
\hline
\end{tabular}




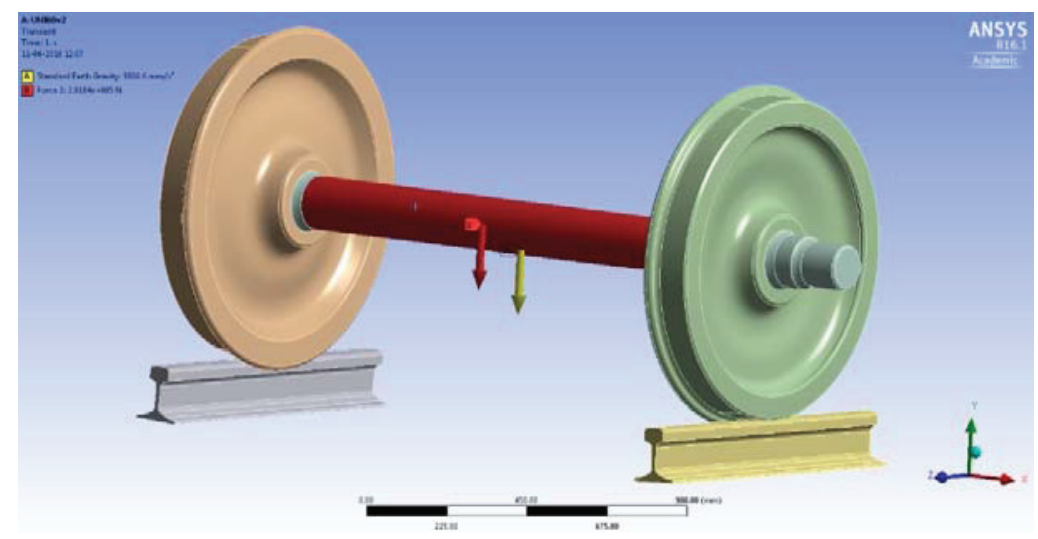

Figure 2: Loads assigned in the model.

program to control automatically, with the stiffness set to update with each iteration. The interface between axle and wheels was modelled as a frictionless contact, considering the interface behaviour as asymmetric. Here, axle was considered as the contact element and wheel was selected as the target. Both the interface formulation and normal stiffness were left to the program to automatically set and stiffness was again set to update with each iteration.

\subsection{Loads and boundary conditions}

The modelled section of railway track is considered to be loaded with a train driven by high speed locomotive WAP-7 of Indian Railways. The locomotive has an axle load 20.5 tonnes with a capacity of hauling trains at speeds of 110 to $140 \mathrm{~km} / \mathrm{h}$, while $24-26$ passenger coaches are attached (with a load of around 1500 tonnes). Fig. 2 shows the loads assigned in the model. An axle load of 20.5 tonnes $(201036 \mathrm{~N})$ is applied vertically downwards on the axle shaft. In addition, acceleration due to gravity ' $\mathrm{g}$ ' is also considered in the model. For the boundary conditions, it is assumed that the rails are fixed on to the ground.

\subsection{Analysis settings}

It was estimated that a total of 458309 nodes and 136943 elements were generated in the model after meshing, considering that axle was meshed as a deformable body with $15 \mathrm{~mm}$ mesh size. The analysis was set with 'Mechanical APDL' solver target. Large deflection and time integration settings were enabled, and for solution, it was considered that both force and displacement should follow a convergence criterion of $0.1 \%$, ensuring that the results will be subject to very less computational errors.

\subsection{Static loading analysis results}

After 961 cumulative iterations completed for simulation of the static railway loading for 1 second, a maximum wheel-rail contact pressure of $1143 \mathrm{MPa}$ was obtained for the applied axle load of 20.5 tonnes. This result is very close to the contact pressure value of $1120 \mathrm{MPa}$ 


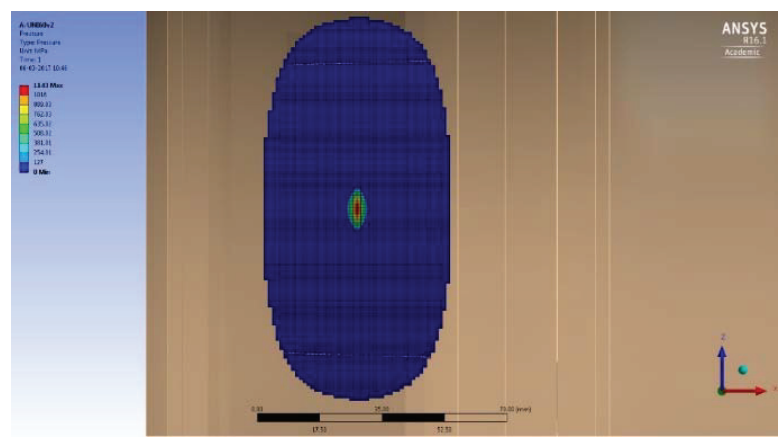

Figure 3: Elliptical contact stress distribution in agreement with Hertz theory.

previously obtained by the authors on a numerical model considered with deformable nature of the wheel-set components. It could very well be seen that the rigid-body analysis completed at a fraction of the time required for finely meshed deformable-body analysis, while being able to deliver results within a difference of $3 \%$, and on the conservative side. It can be seen from Fig. 3 that the contact patch obtained in the analysis was also in good agreement with the Hertz theory, which explains about the elliptical contact stress distribution at the interface between a curved and flat metallic surface, with the maximum intensity located at the centre of the contact patch.

\section{DEVELOPMENT OF 3D MODEL FOR TRANSIENT MOVING LOAD ANALYSES}

A numerical 3D moving load model was further developed for the simulation of actual wheelrolling movement of a loaded wheel-set on a railway track, based on the wheel-rail interface friction. The simulation of an ICF coach bogie wheel-set is considered at the maximum allowed axle load of 20.3 tonnes (for coaches) travelling at a speed of $140 \mathrm{~km} / \mathrm{h}$, the maximum speed at which a train with high speed locomotive WAP-7 operates today. A track length of $50 \mathrm{~m}$ is considered in this model, with the material specifications, wheel-set dimensions, element specifications, contact modelling and analysis settings same as that used in the static analysis.

\subsection{Loads, train velocity and boundary conditions applied}

Fig. 4 shows the load definition and application of train velocity in the model. An axle load of 20.3 tonnes (for fully loaded ICF coaches) is applied along with the acceleration due to gravity ' $g$ ' considered in load definition. A translational joint is created between axle and the ground, applying a velocity of $140 \mathrm{~km} / \mathrm{h}(38889 \mathrm{~mm} / \mathrm{s})$ on the wheel-set relative to the rails. In Fig. 4 the downward arrow shows the applied axle load and the directional train velocity is represented by the arrow in forward direction of rails.

The applied velocity of $140 \mathrm{~km} / \mathrm{h}$ on the axle pulls it forward with the wheels attached onto it. It is to be noted that the axle wheel interface is modelled as frictionless and there is no contribution by any friction in this interface in spinning the wheels. The rotation of wheels occurs explicitly due to the interface friction between wheels and rails, when the wheel is pulled along with axle in the forward direction. This can be particularly helpful in modelling the wearing of wheels and rails, since the model simulates wheel-rolling movement resulting 


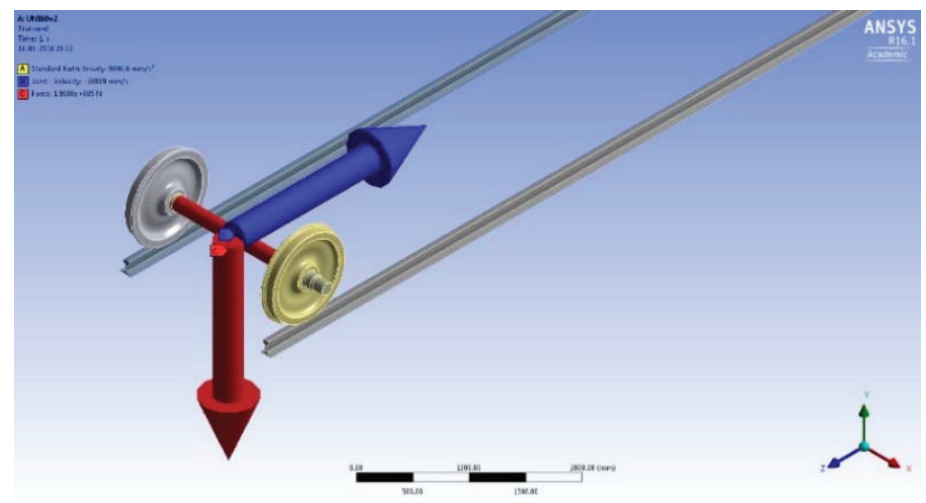

Figure 4: Loads and velocities applied on the axle.

from the interface resistance offered by rails on wheels. A fixed boundary condition is applied under the rails to attach with the ground.

\subsection{Alterations in mesh sizes}

Because of the lengthier rails incorporated in this model, larger element sizes were considered for the meshes, with the following sizes:

- Wheel (surface): $7.5 \mathrm{~mm}$

- Rail (surface): $15 \mathrm{~mm}$

- Axle-wheel interface: $100 \mathrm{~mm}$

- Axle (body): $15 \mathrm{~mm}$

\subsection{Contact definition}

The interface contact definition was similar to static load analysis, except that the rail in this case is longer at $50 \mathrm{~m}$. The modelling of axle-wheel interface remained the same, with the wheel-rail interface being much longer.

\subsection{Analysis settings}

The estimated number of nodes and elements in the model after meshing were 147420 and 43339, respectively. Transient structural analysis was considered with Mechanical APDL solver, and a convergence criterion of $0.1 \%$ was chosen. The analysis was set to incorporate large deflections. The model was assigned with an initial velocity of $140 \mathrm{~km} / \mathrm{h}$ at time $\mathrm{t}=0$ $\mathrm{s}$, and at time $\mathrm{t}=1 \mathrm{~s}$, the velocity remains the same. This implies that there is no acceleration or deceleration of the train considered in the model. It could be said that a glimpse of the train travelling at $140 \mathrm{~km} / \mathrm{h}$ was simulated for 1 second, resulting in a forward wheel-set movement of $38889 \mathrm{~mm}$ on rails within a second.

\subsection{Moving load analysis results}

The 3D moving load analysis was executed, simulating wheel-set rolling on IRS 52 rails with an axle load of 20.3 tonnes and travelling speed of $140 \mathrm{~km} / \mathrm{h}$. After completing 383 cumulative iterations, a maximum wheel-rail contact pressure of $311.45 \mathrm{MPa}$ was observed at the applied train velocity. Running analysis with refined mesh sizes would improve the 


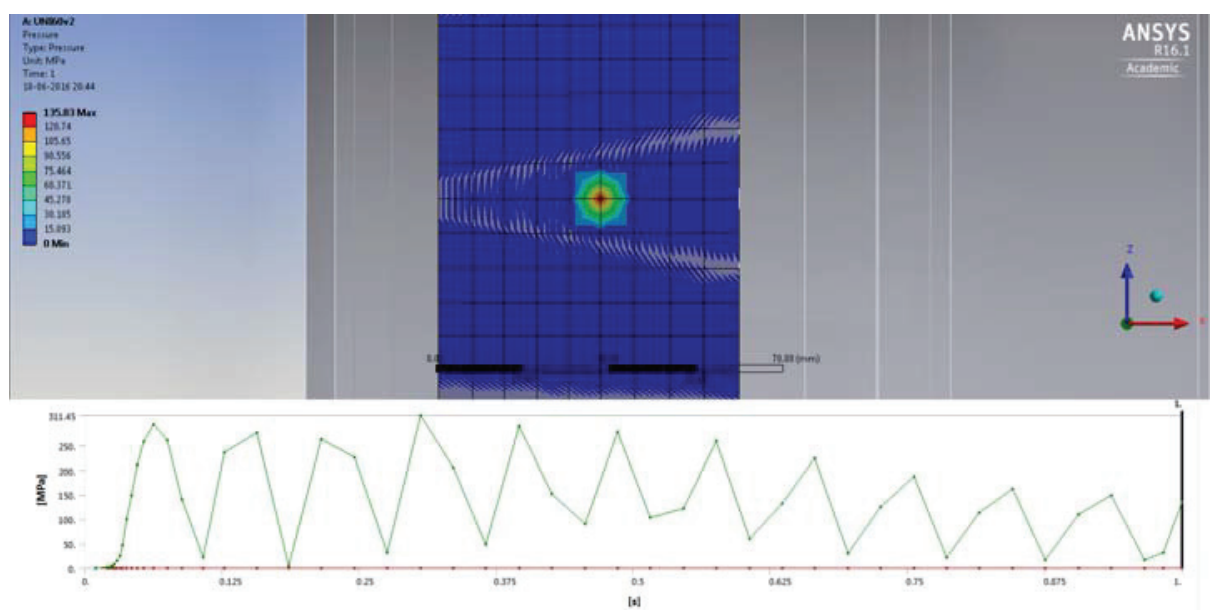

Figure 5: Contact pressure results for the transient moving load analysis.

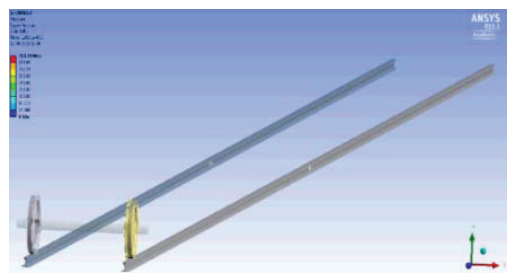

(a)

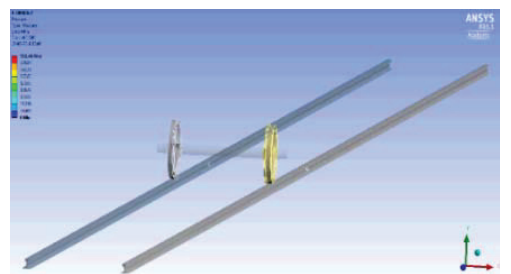

(b)

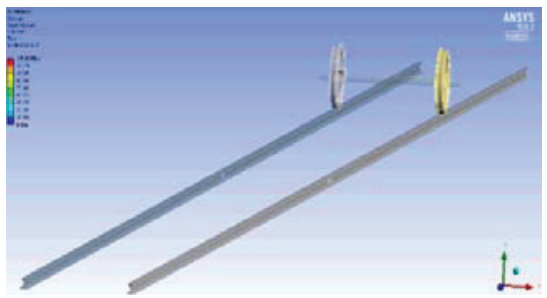

(c)

Figure 6: (a) 3D rigid-body moving load simulation captured at various time instances, $\mathrm{t}=0 \mathrm{~s}$, (b) $0.5 \mathrm{~s}$ and (c) $1 \mathrm{~s}$.

results further. Fig. 5 shows the maximum contact pressures observed for $1 \mathrm{~s}$ of the moving load simulation. The moving load analysis was found to complete just within a total CPU time of 3939 seconds which came down to less than one-twentieth of time taken by a trial analysis run by the authors considering deformable body elements with $50 \mathrm{~mm}$ element size, which took $90175 \mathrm{CPU}$ seconds. The CPU time for deformable analysis would substantially increase further with mesh refinement.

Fig. 6 shows the images of wheel-set travelling on the rails, as captured from three instances in the rigid-body moving load simulation, at time $\mathrm{t}=0 \mathrm{~s}, 0.5 \mathrm{~s}$ and $1 \mathrm{~s}$. 


\section{CONCLUSIONS}

Rigid-body simulation of the railway track system loaded with train wheel-set was found to be a promising alternative to the conventional practice of finely meshed finite element modelling. Rails and wheels were considered to be rigid solid bodies, which in reality can be considered as a logical approximation when compared with the substructure supporting rails. Validation of numerical model developed for contact interface stress analysis was done by comparing the numerical test results with results available from literature on experimental load tests on Italian rail section UNI-60 and regression analyses were done for optimizing the model. The following conclusions were drawn after completion of the model analyses:

- Wheel-rail contact analyses were found to be very sensitive to the surface mesh definition at the contact interface and mesh definition as fine as $1 \mathrm{~mm}$ and below were required to yield reliable test results.

- Static analysis was first performed on an IRS 52 railway track section supporting WAP-7 high speed railway locomotive with an axle load of 20.5 tonnes. Contact interaction analyses performed in this model yielded an interface contact pressure of $1143 \mathrm{MPa}$ at the wheel-rail interface.

- The wheel-rail interface contact patch in the rigid-body model was found to be in close agreement with Hertz theory, having an elliptical stress profile with maximum stress intensity located at the centre of the patch.

- In comparison with deformable-body analysis, rigid-body simulation of WAP-7 locomotive model was found to have results within a very small difference of $3 \%$, and on conservative side.

- 3D moving load models were developed, which could simulate the actual wheel rotation on rails due to the wheel-rail interface contact friction during train movement, instead of using simplified equivalent point load approach.

- Transient moving load simulation of an ICF bogie wheel-set was performed with an applied axle load of 20.3 tonnes travelling at a speed of $140 \mathrm{~km} / \mathrm{h}$, the fastest speed with which an Indian Railway train operates to date.

- The moving load analysis was found to complete just within a total CPU time of 3939 seconds which came down to less than one-twentieth of time taken by an analysis that considers the model to have deformable body elements with $50 \mathrm{~mm}$ element size, taking 90175 CPU seconds to execute completely.

It could be concluded that static and transient rigid-body simulations can be effectively utilized by the railway planning and designing authorities as a fast computing alternative to the conventional methods for design. The operational aspects of railways under mixed loading conditions at variable train speeds can be analysed with ease, which would significantly save the cost and time involved in planning and implementation of high speed railway lines and freight corridors.

\section{RESEARCH CONTRIBUTIONS}

The authors have evaluated the possibilities of utilizing rigid-body physics in simulation of rail-wheel contact interactions and estimation of interface contact stresses that are generally devised from deformable-body analyses. This method proves to be very easy on the computational demands and time associated with finite element analyses by effectively reducing the number of elements required to be processed within the model, while sufficiently being able to portray the contact interactions with much reliability. A 3D transient moving load analysis model was also developed that could simulate the actual wheel rotation 
mechanism on rails due to interface friction, instead of simplifying the load definition into equivalent point loads. The method can be effectively used for analyzing the changes in wheel-rail contact interactions when trains with different axle loads and travel speeds are operating on railway tracks. Tribologists can utilize the wheel rotation simulation for estimating the frictional stresses and wearing rates for different sections of wheels and rails under arduous loading conditions.

\section{REFERENCES}

[1] Basu, D. \& Kameswara Rao N.S.V., Analytical solutions for Euler-Bernoulli beam on visco-elastic foundation subjected to moving load. International Journal for Numerical and Analytical Methods in Geomechanics, 37(8), pp. 945-960, 2013.

[2] Celebi, E., Three-dimensional modelling of train-track and sub-soil analysis for surface vibrations due to moving loads. Applied Mathematics and Computation, 179(1), pp. 209-230, 2006.

[3] Chatterjee, P., Degrande, G., Clouteau, D., Al-Hussaini, T., Arnst, M. \& Othman, R., Numerical modelling of ground borne vibrations from underground railway traffic. Proc. of the 6th National Congress on Theoretical and Applied Mechanics, Ghent, Belgium, 2003.

[4] Karlström, A., An analytical model for ground vibrations from accelerating trains. Journal of Sound and Vibration, 293(3), pp. 587-598, 2006.

[5] Ma, M., Markine, V., Liu, W.N., Yuan, Y. \& Zhang, F., Metro train-induced vibrations on historic buildings in Chengdu, China. Journal of Zhejiang University SCIENCE A, 12(10), pp. 782-793, 2011.

[6] Melaku, S. \& Qiu, H., Transient Dynamic Analysis of Simple Railway Bridge under Train Moving Load. International Conference on Civil Engineering, Energy and Environment, pp. 106-111, 2014.

[7] Minsili, L.S., Xia, H. \& Eko, R.M., Analytical Model of Underground Train Induced Vibrations on Nearby Building Structures in Cameroon: Assessment and Prediction. Leonardo Electronic Journal of Practices and Technologies, 23, pp. 6382, 2013.

[8] Ouyang, H., Moving-load dynamic problems: A tutorial (with a brief overview). Mechanical Systems and Signal Processing, 25(6), pp. 2039-2060, 2011.

[9] Shahraki, M.S.M., Sadaghiani, R.S., Witt, K.J. \& Meier, T., 3D Modelling of Train Induced Moving Loads on an Embankment. Plaxis Bulletin, 36, pp.10-15, 2014.

[10] Xia, H., Cao, Y.M. \& Zhang, N., Numerical analysis of vibration effects of metro trains on surrounding environment. International Journal of Structural Stability and Dynamics, 701, pp. 151-166, 2007.

[11] Yang, Y.B., Hung, H.H. \& Hsu, L.C., Ground vibrations due to underground trains considering soil-tunnel interaction. Interaction \& Multiscale Mech., Int. J, 1(1), pp. 157-175, 2008.

[12] Centre for advanced maintenance technology, A technical guide on derailments. CAMTECH/M/3, Ministry of railways: Government of India, 1998.

[13] Institution of Permanent Way Engineers (India), Tech Diary. Ministry of railways: Government of India, 2008.

[14] Pau, M., Aymerich, F. \& Ginesu, F., Distribution of contact pressure in wheel-rail contact area. Wear, 253(1), pp. 265-274, 2002.

[15] Research Designs \& Standards Organisation, Maintenance manual for BG coaches of ICF design. Ministry of railways: Government of India, 2002. 